\title{
Usage of additional coefficients for the cost of works during the engineering-technical investigation of buildings
}

\author{
Aleksandr Perunov*, and Ivan Doroshin \\ Moscow State University of Civil Engineering, Yaroslavskoe shosse, 26, Moscow, 129337, Russia
}

\begin{abstract}
The questions of frequency of using for some correcting coefficients for definition of cost of works on the engineering technical investigation are presented in the article. These coefficients are specified in recommended cost documents. There suggested the using of some other coefficients, suiting for specific investigation organization, that are not recommended in sourcebooks.

The list of coefficients, considering the complicating factors and conditions of investigation are brought in regulatory document. The frequency of using for these coefficients in the specific laboratory is given. The conditions are described, at which the value of coefficients is correctly defined, that depends on the frequency of use of these coefficients in the explored organization.

The comparison is brought between different regulatory documents (sourcebooks) by which the cost of engineering-technical investigation is calculated. The coefficients are given, that consider complicating factors, used in the specific organization, that is explored, and absent in regulatory documents. The reasons are explained, by which these coefficients must be taken into account at engineering-technical investigation.
\end{abstract}

\section{Introduction}

The very important element of any construction design is the input information for this design, the great part of which consists of data, obtained during the process of engineering survey. The engineering survey may be engineering-geological, engineering-geodesic, engineering-ecological and so on. Among them the special place takes the engineeringtechnical investigation of buildings, that is performed at reconstruction of building and contains information about geometric dimensions of constructions and their condition.

Earlier we wrote about the determination of values of the coefficients, increasing and diminishing the cost of investigation works depending on the influence of attendant factors that complicate or simplify the investigation. But the important is not only the increasing of cost, caused by such factors, but also the set of factors and coefficients itself. In different regulatory documents on definition of investigation cost the different list of factors is brought, besides the very process of engineering-technical investigation, as well as all the construction technologies, is improved, and the set of factors is changed, for example in sourcebooks of MRR (Moscow Regional Rates) for different years.

* Corresponding author: PerunovAS@mgsu.ru 


\section{Materials and Methods}

For carrying out of the study on the theme of determination and frequency of using of additional coefficients at the calculation of cost of engineering-technical investigation of buildings the methodical and scientific literature on the subject was analyzed, and also the statistic methods of data investigation were used on the example of complication of engineering-technical investigation process, corresponding attending factors acting, in the specific organization.

\section{Results}

For example in the last sourcebook of MRR [7], that regulates the determination of the cost of engineering-technical investigation of buildings and structures in Moscow, the next coefficients are recommended to use:

Table 1. Coefficients during the performance of engineering-technical investigations, considering the influence of complicating factors

\begin{tabular}{|c|c|}
\hline Name of coefficient & Value \\
\hline 1. Special order of work in building & 1,25 \\
\hline \multicolumn{2}{|l|}{ 2. Complicated conditions of investigation: } \\
\hline a) possible harm to health at investigation & 1,20 \\
\hline b) strong humidity and high temperature in building & 1,10 \\
\hline c) use of different devices for access to high constructions & 1,15 \\
\hline d) works in the open air or in unheated rooms in winter & 1,30 \\
\hline $\begin{array}{l}\text { e) presence of furniture and equipment in rooms, complicating } \\
\text { the access to constructions }\end{array}$ & 1,10 \\
\hline 3. Historical and cultural value of building & 1,20 \\
\hline \multicolumn{2}{|l|}{ 4. Small constructive value of building: } \\
\hline a) less than $1000 \mathrm{~m}^{3}$ & 2,50 \\
\hline b) less than $2000 \mathrm{~m}^{3}$ & 2,20 \\
\hline c) less than $3000 \mathrm{~m}^{3}$ & 1,80 \\
\hline d) less than $4000 \mathrm{~m}^{3}$ & 1,40 \\
\hline e) less than $5000 \mathrm{~m}^{3}$ & 1,20 \\
\hline f) $5000 \mathrm{~m}^{3}$ and more & 1,00 \\
\hline $\begin{array}{l}\text { 5. Using of project and executive documentation for building, } \\
\text { that simplifies composing of measuring-investigative drawings }\end{array}$ & 0,75 \\
\hline $\begin{array}{l}\text { 6. During investigation there is no measuring of coverings } \\
\text { constructions, defects are marked on the available scheme plans } \\
\text { of floors (on coverings, walls and partitions) }\end{array}$ & 0,75 \\
\hline
\end{tabular}


We bring here not all the coefficients from the sourcebook, only those that are used rather frequently in the organization, on the basis of which data this research is performed.

It is impossible to determine all the coefficients on the basis of data of specific organization, and further we will show which coefficients concretely we may determine more or less correctly using this information. In reality for the determination of complicating of performance of investigation and additional coefficients we need to perform the exploration in several organizations, that will probably bring to improving of the methodic suggested of the coefficients determination

Statistical studies in one organization can't give us, as we told, the correct values of all the coefficients. To define correctly the value of any coefficient it's necessary that in the selected population there are about half of objects with using of this coefficient and without it. That is necessary because in the methodic the coefficient is obtained as relation of some labor indicator considering the action of the factor and without such action, naturally this indicator should be released from the action of all other factors.

On the basis of data of certain organization we obtain approximate frequency of using of several coefficients, as it was told, not all:

coefficient «small constructive volume» (p.4 table 1) has the frequency $45 \%$;

coefficient «winter period of time» (p. 2d) has the frequency $28 \%$;

coefficient «using of stairs and devices» (p. 2c) $-85 \%$;

coefficient «difficulty of access» (p. 2d) - 81\%;

coefficient «preliminary works», used in previous sourcebooks, and absent in the considered sourcebook $-91 \%$;

coefficient «using of available documentation» (p.5) - 32\%;

coefficient «building with specific order of works» (p.1) - 9\%;

coefficient «historical and cultural value» (p.3) - $13 \%$.

The results, represented in Fig.1 say. that the best coefficients for quantitative determination are the coefficient "Small constructive volume", "Winter period of time" and "Using of available documentation". But the coefficient for small constructive volume contains 5 different intervals of constructive volume, and for its definition for these specific intervals we may encounter additional difficulties. By the way it's rather strange, that the coefficient for preliminary works, that was used in $90 \%$ of cases, was eliminated.

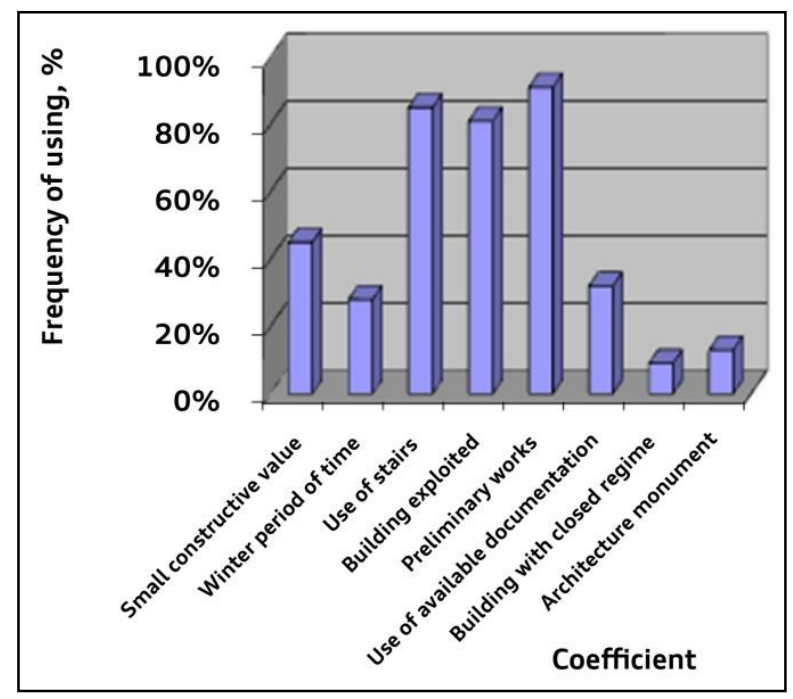

Fig. 1. Frequency of using of coefficients from the sourcebooks 
So, the optimal for the calculation in this case are the coefficients "Small constructive volume", "Winter period of time" and "Using of available documentation". But as we will see further, there are other coefficients, using of which in the estimates of the given organization lets to calculate them correctly, but they aren't present in the sourcebooks, for example in [7]. Besides in the sourcebook [7], opposed to the previous sourcebook [4], there appear new coefficients. So, in particular, due to construction of high-rise buildings and appeared necessity of their investigation, there is an additional coefficient, taking into account the complication of investigative works for the height of building from 30 to $40 \mathrm{~m}$, from 40 to $50 \mathrm{~m}$, higher than $50 \mathrm{~m}$. We have also the coefficient, increasing the cost of investigation, if the building has suffered from fire or flood. So the cost of investigation of a building after fire, flood, and other natural disasters is increased by 30 percent. Certainly the new coefficients, considering modern space-planning solutions and new construction technologies, are necessary for account of appearing additional factors, but their determination also must be correct.

It's necessary to say, that some coefficients, brought in the sourcebooks [7], weren't in fact used in the explored organization. These are the coefficients, related to the investigation of buildings and enterprises with production, harmful for health, with high temperature and humidity. Besides, sometimes the investigation is carried out without measuring of coverings constructions, even visible, e.g. only the checking of floor plans with available drawings is performed, and after the visible defects are marked approximately on these plans, on coverings and walls. That is reflected by corresponding coefficient, but it wasn't also used, most probably because such way of carrying out of works is more related to the visual investigation, for which the special rates are set.

Such conditions of works may be present in other organizations, and the additional coefficients also must be calculated, and after that they also must supplement the single base of coefficients, that is brought in sourcebooks.

Besides, some conditions of labor and performance of investigation don't find their reflection in the sourcebooks, the coefficients for them aren't brought, as told higher. For example, these are the additional expenses for transport at departure of investigation group for the object, at delivery of survey equipment for carrying out of measurings on the object directly, delivery of samples, selected immediately from constructions to the laboratory for conducting of tests, additional verifying calculations with performance of geometric modeling of stress-strained condition of the building, expenses for using of PC. Account of additional transport expenses was carried out in $28 \%$ of cases for this organization, additional verifying calculations were made in $62 \%$ of cases, aditional labor expenses in case of using of PC were revealed in $57 \%$ of objects.

\section{Discussions}

The distribution of frequency of using of the given coefficients is brought in Fig. 2. We told already, that there are additional transport expenses, connected with departure of performers, delivery of equipment to the object, delivery of selected samples to the laboratory. There is an opinion, that we must consider them too. In the past such coefficients often were taken from other sourcebooks, for example from the sourcebook for determination of prices for engineering-geological explorations. Although it was formally illegal, and some customers didn't agree with using of such coefficients. Desides, the building may be situated in Moscow region, and the transport expenses increase. In the sourcebook [4] there was coefficient "The building is situated outside of Moscow", that considered this case, but it isn't brought in the sourcebook [7]. So in the new sourcebook 
there is no way of account of the expenses for additional transport, that may be rather costeffective at the determination of general investigation price.

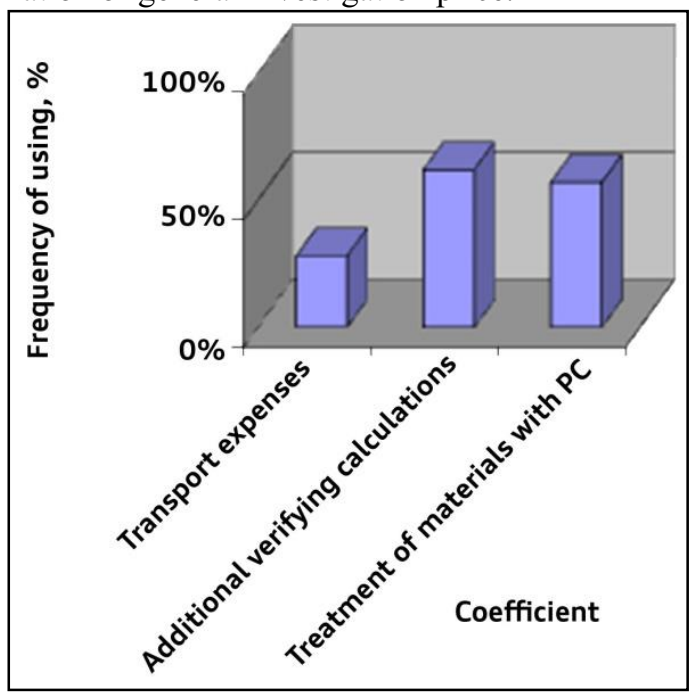

Fig. 2. Frequency of using of coefficients, absent in the sourcebook

As for the coefficient on additional verifying calculations, increasing of labor expenses according to their performance has been observed for a long time and was begun with using of computer programs, with the help of which the spatial calculation of building was made, or geometric 3-dimensional modeling of the whole building and checking of its bearing capacity by the finite element method. Such calculations allow to take into account the stress-strain condition of the whole building, to reflect correctly different loadings and special features of geometric dimensions of constructions. In spite of using of PC, such calculations are more complicated and demand greater labor expenses, than standard calculations by plane scheme. These additional expenses were added to the calculation by specialists by different ways, but customers often excluded them.

\section{Conclusions}

On the basis of told above we may make a conclusion, that not all the coefficients brought in [7] were used in the organization explored, and in the same time we found the additional labor expenses, that take place in reality, but aren't reflected in the sourcebook. That's why we consider, that the additional methodic of calculation is necessary, that would allow to consider these labor expenses both in a specific organization, and during the calculation of cost of engineering-technical investigation for any other firm.

\section{References}

1. Doroshin, I. Methods of calculations of rates, determining the cost of pre-design and design works. Journal of Economy and entrepreneurship 5-1 (82-1) (2017).

2. Doroshin, I. Some features of defining of the cost of design and survey works. Estimate and contract work in construction 3, (18-23) (2015). 
3. «Procedure of determining of the cost of works on technical investigation of constructions of buildings and structures» MRR-3.2.05.02-00. Moscow, GUP «NIAZ» Moscow Architecture Committee, 2000.

4. Recommendations on determining of the cost of works on investigation of technical conditions of constructions of buildings and structures MRR-3.2.05.03-05, Moscow, GUP «NIAZ», 2006.

5. "Sourcebook of basic prices on measuring works and investigations for buildings and structures" SBCP 81-2001-25, Moscow, 2016.

6. «Sourcebook of prices for measuring-investigative and design works for capital repair of buildings and structures» / Moscow, MHM, 1991.

7. «Sourcebook of basic prices on investigation and monitoring of technical condition of building constructions and engineering equipment of buildings and structures" MRR3.2.05.04-07, Moscow, GUP «NIAZ», 2008.

8. Sudar O.Y., Ulybin A.V., Kukushkina G.A., Stroitel'stvo unikal'nyh zdanij i sooruzhenij $572-89,2016$.

9. Davydova A.M. Stroitel'nye materialy, konstrukcii i tekhnologii XXI veka 35-40, 2019.

10. Mohireva A.O., Glebova E.A., Loginova P.V., Nazinyan L.G., Tihonovich N. A., Belousov N. D. Stroitel'stvo unikal'nyh zdanij i sooruzhenij 2 7-22, 2019.

11. Tuhvatullin R. F. Vestnik ekonomiki, prava i sociologii 4 127-133, 2015.

12. Ulybin A. V., Zubkov S.V. Inzhenerno-stroitel'nyj zhurnal 7 53-56, 2010.

13. Butyrin A.Yu., Danilkin I.A. Nedvizhimost': ekonomika, upravlenie 4 78-81, 2016. 